\title{
Spindle Cell Sarcoma of Submandibular Salivary Gland: A Rare Presentation
}

\author{
${ }^{1}$ Priti Rakesh Dhoke, ${ }^{2}$ Vivek Vishwasji Harkare, ${ }^{3}$ Nitin Vasant Deosthale \\ ${ }^{4}$ Sonali Prabhakar Khadakkar, ${ }^{4}$ Kanchan Sandeep Dhote, ${ }^{5}$ Gopal Gurjar \\ ${ }^{1}$ Lecturer, Department of ENT, NKP Salve Institute of Medical Sciences and Research Centre, Nagpur, Maharashtra, India \\ ${ }^{2}$ Professor and Head, Department of ENT, NKP Salve Institute of Medical Sciences and Research Centre, Nagpur, Maharashtra, India \\ ${ }^{3}$ Professor, Department of ENT, NKP Salve Institute of Medical Sciences and Research Centre, Nagpur, Maharashtra, India \\ ${ }^{4}$ Assistant Lecturer, Department of ENT, NKP Salve Institute of Medical Sciences and Research Centre, Nagpur, Maharashtra, India \\ ${ }^{5}$ Assistant Professor, Department of Surgery, NKP Salve Institute of Medical Sciences and Research Centre, Nagpur, Maharashtra, India
}

Correspondence: Priti Rakesh Dhoke, Lecturer, Department of ENT, NKP Salve Institute of Medical Sciences and Research Centre, Nagpur, Maharashtra, India, e-mail: drpritidhoke@ rediffmail.com

\section{ABSTRACT}

Objective: To report a rare case of spindle cell sarcoma of submandibular salivary gland, with intraoral extension with pathological dilemma. Case report: A 40-year-old male presented with swelling and pain in right submandibular area since 1 year. Right submandibular gland excision with intraoral mass excision was done with reconstruction of floor of mouth. Postoperative histopathology was suggestive of low-grade malignant tumor with differential diagnosis of acinic cell tumor, vascular tumor and myoepithelial tumor. The immunohistochemistry report revealed spindle cell sarcoma with high degree of vascularity. Based on this report postoperative radiotherapy was planned.

Conclusion: According to literature, spindle cell sarcoma of submandibular salivary gland has not been reported yet. This case is presented for its uniqueness of its site, extension and histopathological dilemma.

Keywords: Soft tissue sarcoma, Surgery, Radiotherapy.

\section{INTRODUCTION}

Sarcomas are relatively uncommon tumors, accounting for $1 \%$ of all malignancies. Head and neck sarcomas are rare account for about $10 \%$ of all sarcomas. ${ }^{1}$ Primary sarcoma of salivary gland is extremely rare and may be confused with other primary salivary gland neoplasms. This distinction is critical, as the treatment of salivary gland sarcoma differs significantly from the therapy of the more common tumors typically found in these glands. M ost of the salivary gland tumors are epithelial, while sarcomas of salivary gland are mesenchymal in origin. Spindle cell sarcoma comprises only a small number of mesenchymal tumors in the salivary gland. ${ }^{2}$

\section{CASE REPORT}

A 40-year-old male patient came to ENT OPD, presented with painful swelling in the right submandibular region since 1 year and mass in the oral cavity since 30 days. There was intermittent bleeding from oral mass since 20 days. On examination, the right submandibular salivary gland was enlarged measuring $4 \times 3 \mathrm{~cm}$, it was tender and firm in consistency. Examination of oral cavity revealed a reddish mass in the floor of mouth toward right side measuring approximately $3 \times 2 \mathrm{~cm}$, extending from 1st premolar to 2nd molar tooth (Fig. 1). On pal pation, it was a well-defined

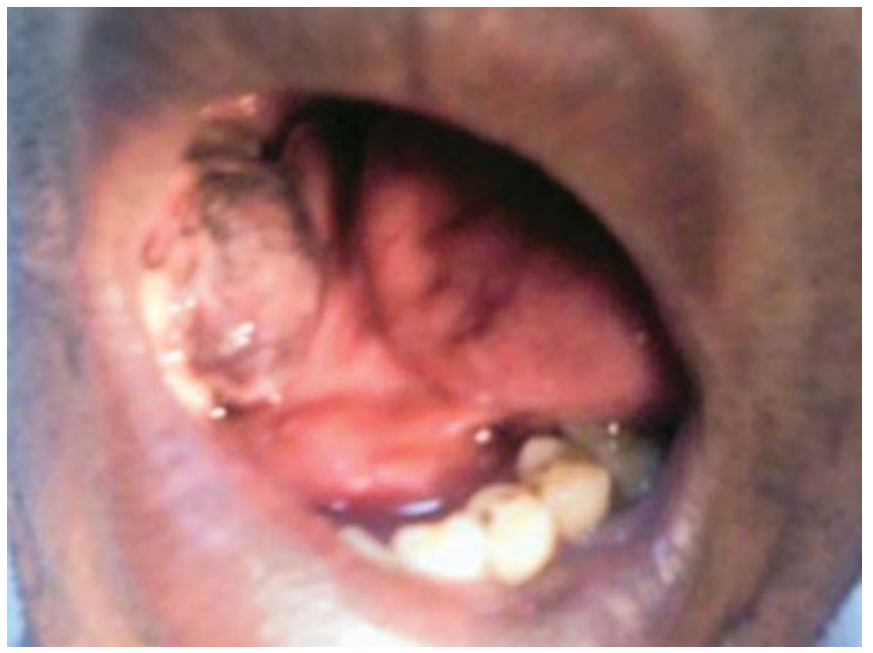

Fig. 1: Intraoral extension of tumor mass

tender mass which appeared to be in continuity with the external swelling. The mass was fragile and bled occasionally on manipulation. Biopsy from the oral mass was suggestive of pleomorphic adenoma. CT scan revealed a large moderately enhancing mass in the right submandibular region and was in continuity with the intraoral mass. Right submandibular gland was excised with intraoral mass and the defect in the floor of mouth was reconstructed using platysmal flap. Postoperative histopathology was suggestive 


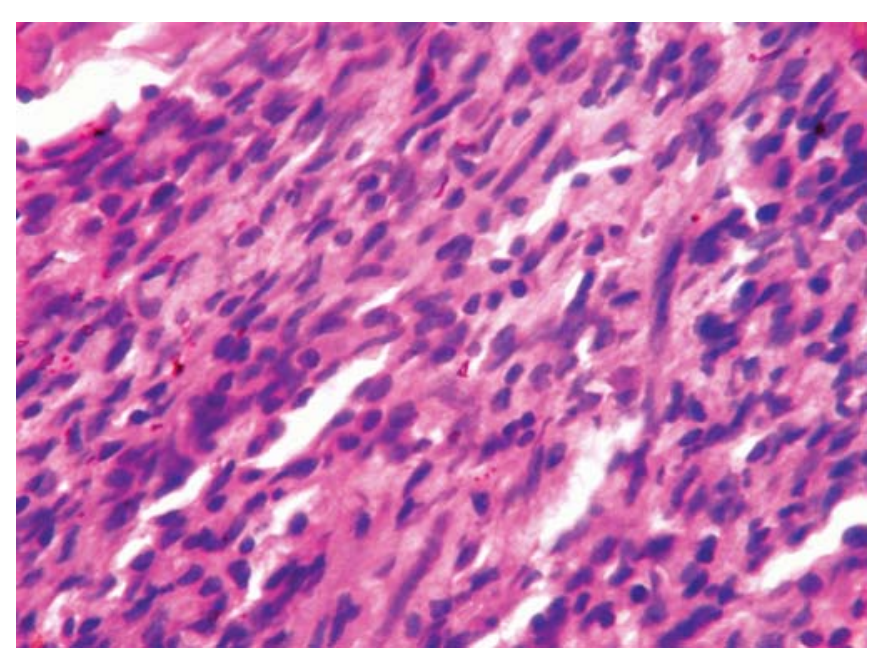

Fig. 2: Microscopic view showing spindle cell proliferation

of low-grade malignant tumor with differential diagnosis of acinic cell tumor, vascular tumor and myoepithelial tumor (Fig. 2). B ecause of postoperative histopathological dilemma of diagnosis, the specimen was sent for immunohistochemistry which revealed it to be spindle cell sarcoma of submandibular salivary gland. The patient underwent radiotherapy and at the end of 1 year there were no signs of recurrence.

\section{DISCUSSION}

There are several reports of sarcoma arising from soft tissue $(80 \%)$ and bones $(20 \%)$ of various parts of the body. There are more than 30 histologic subtypes of sarcoma described in literature. A pproximately, $10 \%$ of these sarcomas occur within head and neck. ${ }^{1}$ Soft tissue sarcoma arises from the mesenchyme, including muscle, endothelial cell, cartilage of the supporting el ements. Primary sarcoma of the salivary glands behaves like other soft tissue sarcomas and the prognosis correlates with tumor size type of the sarcoma and the degree of histopathological differentiation. ${ }^{4}$

$\mathrm{H}$ ead and neck sarcomas are aggressive tumors occurring more commonly in men than in women. They unusually present as an enlarging painless mass. ${ }^{3}$ The macroscopic appearance of sarcoma varies considerably. M ost of them appear as a fleshly mass, with its consistency depending on the relative proportion of tumor and vascular tissue. Hemorrhages commonly occur owing to very thin-walled veins, which in some places are represented merely by venous spaces. M icroscopically, these tumors are partially or completely encapsulated. They infiltrate through the capsule into the surrounding normal salivary gland and adjacent adipose or muscular tissue, with the extent of invasion varying from case to case. ${ }^{5} \mathrm{H}$ istologically, spindle cell sarcoma shows spindle cell proliferation in the form of intersecting bundles in richly vascular and myxoid stroma. Immunohistochemistry is of real help to differentiate the origin of sarcoma and is instrumental in narrowing the differential diagnosis.

Imaging studies are used to demonstrate the extent of tumor involvement, which forms the basis of treatment modalities to be used. Spindle cell sarcoma is treated primarily with surgery and often adjuvant or neoadjuvant radiations as primary therapy. ${ }^{6}$ A round $10-15 \%$ of head and neck sarcoma shows regional metastasis. Distant metastasis is rare at presentation but presence of regional metastasis should prompt a search for distant metastasis. Radi otherapy is of little value in cases of metastasis. Sarcomas are often susceptible to anticancer drugs. ${ }^{7}$ L ocal recurrence which is the common reason for treatment failure is common.

\section{SUMMARY}

The aim of presenting this case is to make aware the surgeons about the possibility of sarcoma in salivary gland tumors and importance of immunohistochemistry for differentiation of sarcoma.

\section{ACKNOWLEDGMENT}

We are thankful to Dr M rs Sadhana M ahore, HOD and Professor, D epartment of Pathology for her cooperation in reaching to the histopathological diagnosis.

\section{REFERENCES}

1. M cgurk M ark, Cassoni A nna, Pitkin Lisa. Cysts and tumours in and around the jaws, including sarcoma. In: Gleeson M ichael (Ed). Scott-Brown's Otorhinolaryngology, Head and Neck Surgery (7th ed), L ondon: Hodder A rnold publisher, 2008;1931.

2. Khalkhali Kazem, A zizi Mohmmad-Reza, A tighedhi Saeid. A fibrous histocytoma of intermediate malignancy arisen from the parotid gland. A rchives of I ranian Medicine 2007;10(1): 100-03.

3. Elsele David W, Johns Michael E. Salivary gland neoplasms. In: J ohnson J onas T, G luckman Jack, Pou A nna M (Eds). Head and Neck Surgery-Otolaryngology (3rd ed). Philadelphia: Lippincott W illiams and W ilkins 2001;2:1284.

4. L una M A, Tortoledo M E, Ordonez NG, et al. Primary sarcoma of the major salivary gland. A rchives of O tolaryngology- Head and Neck Surgery 1991;117:302-06.

5. Colline Paola, Poul HB, Sorenses, Shreyaskumar Patel, et al. Seminar in Oncology 2009;36(4):324-37.

6. Kane Shubhada V, N Bagwan Izhar. M yoepithelial carcinoma of the salivary glands. A rchives of otolaryngology $-\mathrm{Head}$ and Neck Surgery 2010;136(7):702-12.

7. M ann Charles V. Tumours; cysts; ulcers; sinuses. In: Charles V Mann, RCG Russell, W illiams Norman S (Eds). Bailey and Love's short practice of surgery, London. A rnold publishers (22nd ed), 1995;pp 118. 